\title{
Predictive scoring systems for in-hospital mortality due to acutely decompensated liver cirrhosis in Indonesia
}

\author{
Saut Horas H. Nababan ${ }^{1 *}$, Arif Mansjoer ${ }^{2}$, Achmad Fauzi ${ }^{3}$ and Rino A. Gani ${ }^{1}$
}

\begin{abstract}
Background: Acutely decompensated liver cirrhosis is associated with high medical costs and negatively affects productivity and quality of life. Data on factors associated with in-hospital mortality due to acutely decompensated liver cirrhosis in Indonesia are scarce. This study aims to identify predictors of in-hospital mortality and develop predictive scoring systems for clinical application in acutely decompensated liver cirrhosis patients.

Methods: This was a retrospective cohort study using a hospital database of acutely decompensated liver cirrhosis data at Cipto Mangunkusumo National General Hospital, Jakarta (2016-2019). Bivariate and multivariate logistic regression analyses were performed to identify the predictors of in-hospital mortality. Two scoring systems were developed based on the identified predictors.
\end{abstract}

Results: A total of 241 patients were analysed; patients were predominantly male (74.3\%), had hepatitis B (38.6\%), and had Child-Pugh class B or C cirrhosis (40\% and 38\%, respectively). Gastrointestinal bleeding was observed in 171 patients (70.9\%), and 29 patients (12.03\%) died during hospitalization. The independent predictors of in-hospital mortality were age (adjusted OR: 1.09 [1.03-1.14]; $p=0.001$ ), bacterial infection (adjusted OR: 6.25 [2.31-16.92]; $p<0.001$ ), total bilirubin level (adjusted OR: 3.01 [1.85-4.89]; p <0.001) and creatinine level (adjusted OR: 2.70 [1.20-6.05]; $p=0.016$ ). The logistic and additive scoring systems, which were developed based on the identified predictors, had AUROC values of 0.899 and 0.868 , respectively.

Conclusion: The in-hospital mortality rate of acutely decompensated liver cirrhosis in Indonesia is high. We have developed two predictive scoring systems for in-hospital mortality in acutely decompensated liver cirrhosis patients.

Keywords: Liver cirrhosis, Acute decompensation, In-hospital mortality, Scoring system, Prognosis

\section{Background}

Globally, from 2007 to 2017, there was a 15\% increase in mortality due to liver cirrhosis and chronic liver disease[1]. During the 2000-2015 period, there was an increase in the incidence of liver cirrhosis in the Asia Pacific region, including Indonesia [2]. In contrast with

\footnotetext{
*Correspondence: sautnbbn83@gmail.com

${ }^{1}$ Hepatobiliary Division, Internal Medicine Department, Cipto Mangunkusumo National General Hospital, Faculty of Medicine, Universitas Indonesia, Jl. Diponegoro No. 71, Jakarta 10430, Indonesia Full list of author information is available at the end of the article
}

that in Japan, South Korea, and China, which experienced a decrease in mortality due to liver cirrhosis, mortality is increasing in Indonesia [3]. In addition, cirrhotic patients have a lower productivity level and a lower quality of life than people without cirrhosis [4].

Liver cirrhosis is the final stage in the natural course of chronic liver disease. Prognostic studies show that cirrhotic patients are heterogeneous, with different survival rates. A total of $5 \%-7 \%$ of patients with liver cirrhosis at the compensated stage will experience acute decompensation within one year [5]. The in-hospital mortality in 
acutely decompensated liver cirrhosis patients has been reported to vary from $4 \%$ to $11.6 \%$ due to differences in study designs, etiology, and drug availability $[6,7]$. Several factors were associated with in-hospital mortality among acutely decompensated liver cirrhosis patients, such as demographic factors, degree of liver dysfunction, complications associated with portal hypertension, and extrahepatic organ dysfunction. However, the effect of these factors independently on mortality is not yet fully understood. Other predictors of mortality have also been studied, such as the presence of comorbidities, bacterial infection, markers of infection, such as $\mathrm{C}$-reactive protein and procalcitonin, and hyponatremia [8-12].

Several scoring systems have been developed to predict mortality in patients with acutely decompensated liver cirrhosis, such as the Child-Pugh score and Model for End-stage Liver Disease (MELD). These scoring systems are effective in predicting 3- and 6-month mortality but less accurate in predicting in-hospital mortality [13]. The MELD-Na score can predict in-hospital mortality in liver cirrhosis patients in an intensive care setting with modest accuracy (area under the receiver operating characteristics curve (AUROC): 0.77-0.81) [14]. The chronic liver failure-acute decompensation (CLIF-AD) scoring system has been developed to predict short-term and longterm mortality in acutely decompensated liver cirrhosis patients, but it has not been validated in our population [7].

Liver cirrhosis is still an important health issue in Indonesia. According to the Indonesian national health insurance program, liver cirrhosis is one of the diseases with a catastrophic cost expenditure [15]. However, data on in-hospital mortality of acutely decompensated liver cirrhosis in Indonesia are still limited. This study aims to identify predictors of in-hospital mortality and develop predictive scoring systems for clinical application in acutely decompensated liver cirrhosis patients.

\section{Methods}

This study was performed in accordance with the ethical principles of the Declaration of Helsinki (7th revision, 2013). This study was approved by the Ethics Committee of the Faculty of Medicine, Universitas Indonesia (No.KET-1368/UN2.F1/ETIK/PPM.00.02/2019) and the Institutional Review Board of Cipto Mangunkusumo National General Hospital (No.LB.02/221/0107/2020). This was a retrospective cohort study of liver cirrhosis patients aged $\geq 18$ years with acute decompensation at Cipto Mangunkusumo National General Hospital, a tertiary referral hospital in Jakarta, Indonesia, between January 2016 and December 2019. All patient's data were extracted from the hospital paper-based and electronic health records. All clinical variables, including also laboratory test, imaging, biopsy and endoscopy results were identified. The diagnosis of liver cirrhosis was based on liver biopsy or by a combination of clinical examination, imaging (ultrasound, CT/MRI, transient elastography), and laboratory results. Acute decompensation was defined as (1) grade 2-3 ascites that occurred for the first time or recurred after improvement with previous therapy; (2) hepatic encephalopathy that occurred for the first time or recurred after improvement with previous therapy; and (3) gastrointestinal bleeding secondary to portal hypertension, including esophageal and gastric variceal bleeding. Of the 894 patient records, 302 showed incomplete or lost data. So, we reviewed 592 acutely decompensated liver cirrhotic patients. The exclusion criteria were pregnancy, HIV coinfection $(\mathrm{n}=31)$, immunosuppressive treatment $(\mathrm{n}=5)$, advanced hepatocellular carcinoma (beyond the Milan criteria) $(n=255)$, postoperative or post-liver transplant, hospitalization for only diagnostic purposes or elective procedures, and hospitalization for less than $24 \mathrm{~h}(\mathrm{n}=60)$. A total of 241 patients were included in the final analysis (Additional file 1: Figure S1). Thirteen clinical variables were recorded at hospital admission: (1) age, (2) number of Charlson comorbidities, (3) history of decompensation, (4) hepatic encephalopathy, (5) bacterial infection, (6) mean arterial pressure (MAP), (7) $\mathrm{SpO}_{2} / \mathrm{FiO}_{2}$ ratio, (8) neutrophil count, (9) sodium level, (10) albumin, (11) total bilirubin, (12) creatinine, and (13) prothrombin time. Bacterial infections were defined according to the conventional criteria as previously reported [16], after a detailed review of all diagnostic components of the health records.

All patients with acutely decompensated liver cirrhosis received standard medical therapy based on international consensus. Patients with ascites underwent ascitic tap and ascitic fluid analysis. Patients with gastrointestinal bleeding received vasoactive therapy, blood transfusion, and endoscopy. Ligation was performed for oesophageal varices, and cyanoacrylate glue injection was performed for gastric varices. Patients with hepatic encephalopathy received lactulose therapy. Empirical antibiotic administration was based on the local guidelines for the use of antibiotics issued by Cipto Mangunkusumo National General Hospital. None of the patients underwent the transjugular intrahepatic portosystemic shunt (TIPSS) procedure. None of the patients received liver-support therapy, such as plasmapheresis, or underwent liver transplantation.

\section{Statistical analysis}

All data were validated before they were processed using STATA software (release 15.0, STATA Corporation, College Station, TX). Continuous variables are presented as medians (minimum-maximum) or means \pm standard 
deviations, as appropriate. Categorical variables are presented as frequencies (percentages). Bivariate simple logistic regression and multivariate logistic regression analyses were performed to identify independent predictors of in-hospital mortality. For the development of predictive scoring systems, variables with a $p$-value of $<0.25$ in the bivariate analysis were entered into the multivariate logistic regression analysis using the backward stepwise method. The performance of the scoring systems was evaluated by the Hosmer-Lemeshow test and visually presented as a calibration plot. The discriminatory power was evaluated by the area under the ROC (AUROC) curve. Using receiver operating characteristic (ROC) curve analysis, the cut-off point with optimum sensitivity and specificity to predict in-hospital mortality was determined. The discrimination ability of our scoring systems was further assessed by comparing its AUROC with those of other scores such as MELD, MELD-Na and CLIF-C OF. International normalized ratio (INR) was not available for 56 patients. Since INR values correlated well with prothrombin time ratio, INR values were imputed using regression imputation with Expectation Maximization (EM) method with prothrombin time ratio as predictor. A $p$-value of $<0.05$ was considered significant.

\section{Results}

\section{Baseline characteristics}

The patients' baseline characteristics and comparisons between survivors and nonsurvivors are presented in Table 1. In total, 241 patients were included, and 29 patients $(12.03 \%)$ died during hospitalization. A total of $74.3 \%$ of patients were male, with a mean age of 53 years. The most common etiologies were hepatitis B (38.6\%) and hepatitis $C$ viruses (29\%). Most of the patients were classified as having Child-Pugh class B or C cirrhosis ( $40 \%$ and $38 \%$, respectively), with a median score of 9 . A previous history of acute decompensation was noted in $20 \%$ of the cases. The most common comorbidities were diabetes mellitus (33.6\%) and hypertension (13.3\%). The most common acute decompensation was gastrointestinal bleeding (70.9\%), followed by hepatic encephalopathy (26.9\%) and ascites (23.6\%). Pneumonia was the most common infection (22\%). According to the European Association for the Study of the Liver (EASL) definition for Acute-on-Chronic Liver Failure (ACLF) [17], approximately $75 \%$ of our patients had no ACLF at hospital admission.

\section{The independent predictors of in-hospital mortality}

For logistic regression analysis, variables with skewed distribution were transformed into natural logarithm (neutrophil count, total bilirubin, creatinine) or 1/square form (prothrombin time). The $\mathrm{SpO} 2 / \mathrm{FiO} 2$ ratios were converted into categorical data using the median value as the cut-off ( $<460$ or $\geq 460)$. The bivariate analysis showed that age, hepatic encephalopathy, bacterial infection, the $\mathrm{SpO}_{2} / \mathrm{FiO}_{2}$ ratio, the neutrophil count, the sodium level, albumin, the total bilirubin level, the creatinine level, and prothrombin time were significant predictors of in-hospital mortality. The multivariate analysis showed that age (adjusted OR: 1.09; 95\% CI: 1.03-1.14), bacterial infection (adjusted OR: 6.25; 95\% CI: 2.31-16.92), the total bilirubin level (adjusted OR: 3.01; 95\% CI: 1.85-4.89) and the creatinine level (adjusted OR: 2.70; 95\% CI: 1.206.05) were independent predictors of in-hospital mortality in acutely decompensated liver cirrhosis patients. The results are summarized in Table 2.

\section{Development of scoring systems Logistic scoring system}

Based on the multivariate logistic regression analysis (Table 3), we established the following predictive model:

$$
\begin{aligned}
\text { Logistic score }= & 0.086 \times \text { age }(\text { year })+1.834 \\
& \times \text { bacteria } \operatorname{lnfection}(0 \text { if absent, } 1 \text { if present }) \\
& +1.101 \times \ln (\text { total bilirubin, } \mathrm{mg} / \mathrm{dL}) \\
& +0.994 \times \ln (\text { creatinine }, \mathrm{mg} / \mathrm{dL})-9.299
\end{aligned}
$$

The range for the total logistic score was $-9.520-5.670$. The probability of in-hospital mortality was calculated by equation: $\mathrm{p}=1 /(1+\exp (-\mathrm{y}))$, with $\mathrm{y}=0.999 \times$ logistic score-0.019. This logistic score produced an AUROC of 0.899 (95\% CI: 0.846-0.952), and a cut-off value $\geq-1.8184$ had a sensitivity of $82.8 \%$ and specificity of $83 \%$ (Fig. 1). The observed and expected probabilities of in-hospital mortality were similar (Additional file 1: Table S1, Figure S2). The Hosmer-Lemeshow test indicated a good fit $\left(x^{2}=12.60 ; p=0.1265\right)$. The AUROC of the logistic score was significantly better than those of MELD, MELD-Na or CLIF-C OF score $(0.826$ [ $p=0.0432]$, $0.831[p=0.0142]$ and $0.752[p=0.0005]$ respectively) (Table 6).

\section{Additive scoring system}

For the development of the additive scoring system, continuous variables were converted into categorical variables: age $<57$ or $\geq 57$ years, total bilirubin $<3$ or $\geq 3 \mathrm{mg} /$ $\mathrm{dl}$, and creatinine $<1.1$ or $\geq 1.1 \mathrm{mg} / \mathrm{dl}$. Based on the multivariate logistic regression analysis (Table 4), the scores for each variable were determined by dividing the $\mathrm{z}$ value $(\mathrm{B} / \mathrm{SE})$ by the smallest value (2.27) and rounding to the nearest 0.5 . The additive scoring system for in-hospital mortality is presented in Table 5 . The total additive score ranges from 0 (no risk factors are present) to 5 (the subject has all risk factors). The probability of 
Table 1 Baseline characteristics of the study population

\begin{tabular}{|c|c|c|c|}
\hline Characteristic & Entire cohort $(n=241)$ & Discharged alive $(n=212)$ & $\begin{array}{l}\text { Died during } \\
\text { hospitalization } \\
(n=29)\end{array}$ \\
\hline Age (year), mean $\pm S D$ & $53.4 \pm 12.03$ & $52.25 \pm 11.5$ & $61.5 \pm 13.02$ \\
\hline \multicolumn{4}{|l|}{ Sex, n (\%) } \\
\hline Male & $179(74.3)$ & $162(76.4)$ & $17(58.6)$ \\
\hline Female & $62(25.7)$ & $50(23.6)$ & $12(41.4)$ \\
\hline \multicolumn{4}{|l|}{ Etiology, n (\%) } \\
\hline Hepatitis B & 93 (38.6) & $84(39.6)$ & $9(31)$ \\
\hline Hepatitis C & $70(29)$ & $57(26.9)$ & $13(44.8)$ \\
\hline Hepatitis B \& C & $5(2.1)$ & $5(2.4)$ & $0(0)$ \\
\hline NAFLD & $3(1.3)$ & $3(1.4)$ & $0(0)$ \\
\hline Alcohol & $1(0.04)$ & $1(0.5)$ & $0(0)$ \\
\hline Cryptogenic & $69(28.6)$ & $62(29.25)$ & $7(24.14)$ \\
\hline \multicolumn{4}{|l|}{ Child-Pugh, n (\%) } \\
\hline A & $53(22)$ & $52(24.5)$ & $1(3.4)$ \\
\hline B & $96(40)$ & $91(42.9)$ & $5(17.2)$ \\
\hline C & $92(38)$ & $69(32.5)$ & $23(79.3)$ \\
\hline Score, median (min-max) & $9(5-15)$ & $8(5-15)$ & $11(6-14)$ \\
\hline HCC (within the Milan Criteria), n (\%) & $4(1.7)$ & $4(1.89)$ & $0(0)$ \\
\hline \multicolumn{4}{|l|}{ Comorbidities, n (\%) } \\
\hline Diabetes mellitus & $81(33.6)$ & $67(31.6)$ & $14(48.3)$ \\
\hline Hypertension & $32(13.3)$ & $30(14.1)$ & $2(6.9)$ \\
\hline \multicolumn{4}{|l|}{ Charlson comorbidities, n (\%) } \\
\hline None & $138(57.3)$ & $124(58.5)$ & $14(48.3)$ \\
\hline 1 & 77 (31.9) & $66(31.1)$ & $11(37.9)$ \\
\hline 2 & $22(9.1)$ & $18(8.5)$ & $4(13.8)$ \\
\hline$\geq 3$ & $4(1.6)$ & $4(1.9)$ & $0(0)$ \\
\hline Gastrointestinal bleeding, n (\%) & $171(70.9)$ & $157(74)$ & $14(48.3)$ \\
\hline \multicolumn{4}{|l|}{ Hepatic encephalopathy, n (\%) } \\
\hline Grade I-II & $49(20.3)$ & $36(16.9)$ & $13(44.8)$ \\
\hline Grade III-IV & $16(6.6)$ & $14(6.6)$ & $2(6.9)$ \\
\hline Ascites, n (\%) & $57(23.6)$ & $46(21.7)$ & $11(37.9)$ \\
\hline Bacterial infection, n (\%) & $61(25.3)$ & $41(19.3)$ & $20(68.9)$ \\
\hline Pneumonia & $53(22)$ & $34(16)$ & $19(65.5)$ \\
\hline Spontaneous bacterial peritonitis & $8(3.3)$ & $5(2.3)$ & $3(10.3)$ \\
\hline Urinary tract infection & $4(1.6)$ & $3(1.4)$ & $1(3.4)$ \\
\hline Empyema & $1(0.4)$ & $1(0.47)$ & $0(0)$ \\
\hline Skin infection & $4(1.7)$ & $4(1.88)$ & $0(0)$ \\
\hline Previous acute decompensation, n (\%) & $48(20)$ & $44(20.7)$ & $4(13.8)$ \\
\hline $\mathrm{MAP}(\mathrm{mmHg})$, mean $\pm \mathrm{SD}$ & $83.7 \pm 14.7$ & $84.2 \pm 14.6$ & $80.7 \pm 14.9$ \\
\hline $\mathrm{SpO}_{2} / \mathrm{FiO}_{2}$ ratio & $461.9(84.21-476.2)$ & $466.6(84.21-476.2)$ & $306.2(104.21-476.2)$ \\
\hline Leucocyte count $\left(\times 10^{3} / \mu \mathrm{L}\right)$ & $8.4(1.11-42.1)$ & $8.06(1.11-42.1)$ & $13.2(3.2-30.7)$ \\
\hline Neutrophil count $\left(\times 10^{3} / \mu \mathrm{L}\right)$ & $5.9(0.62-37.05)$ & $5.8(0.62-37.05)$ & $10.2(1.71-27.27)$ \\
\hline Albumin $(\mathrm{mg} / \mathrm{dl})$, mean $\pm \mathrm{SD}$ & $2.7 \pm 0.6$ & $2.8 \pm 0.6$ & $2.5 \pm 0.5$ \\
\hline Total bilirubin (mg/dl) & $2.02(0.4-57.8)$ & $1.9(0.4-40.9)$ & $4.9(0.8-57.8)$ \\
\hline Creatinine (mg/dl) & $0.9(0.13-9.3)$ & $0.9(0.3-5.7)$ & $1.3(0.13-9.3)$ \\
\hline Sodium (mg/dl), mean \pm SD & $134.9 \pm 6.4$ & $135.5 \pm 6.2$ & $130.8 \pm 6.4$ \\
\hline Prothrombin time (sec) & $13.3(9.9-120)$ & $12.8(9.9-120)$ & $15.4(11-42.6)$ \\
\hline MELD & $12.8(6.4-43.5)$ & $12.4(6.4-39.6)$ & $22.8(8.4-43.5)$ \\
\hline MELD-Na & $15.7(6.4-43.3)$ & $14.7(6.4-39.6)$ & $25.9(12.6-43.3)$ \\
\hline
\end{tabular}


Table 1 (continued)

\begin{tabular}{|c|c|c|c|}
\hline Characteristic & Entire cohort $(n=241)$ & Discharged alive $(n=212)$ & $\begin{array}{l}\text { Died during } \\
\text { hospitalization } \\
(\mathrm{n}=29)\end{array}$ \\
\hline CLIF-C OF score & $7(6-13)$ & $7(6-13)$ & $9(6-13)$ \\
\hline \multicolumn{4}{|l|}{ ACLF grade, $n(\%)^{a}$} \\
\hline No ACLF & $180(74.7)$ & $169(79.7)$ & $11(37.9)$ \\
\hline Grade 1 & $44(18.3)$ & $33(15.6)$ & $11(37.9)$ \\
\hline Grade 2 & $12(5)$ & $6(2.8)$ & $6(20.7)$ \\
\hline Grade 3 & $5(2.1)$ & $4(1.9)$ & $1(3.4)$ \\
\hline \multicolumn{4}{|l|}{ Causes of death, n (\%) } \\
\hline Septic shock & & & $13(44.8)$ \\
\hline Hypovolemic shock & & & $2(6.9)$ \\
\hline Respiratory failure & & & $8(27.6)$ \\
\hline Liver failure & & & $1(3.4)$ \\
\hline Cardiac arrest & & & $3(10.3)$ \\
\hline Cause unknown & & & $2(6.9)$ \\
\hline
\end{tabular}

Data are presented as medians (minimum-maximum) unless otherwise stated. MAP, Mean arterial pressure; MELD-Na, Model for end-stage liver disease-sodium; CLIF-C OF, Chronic liver failure-consortium organ failure; ACLF, Acute-on-chronic liver failure; NAFLD, Nonalcoholic fatty liver disease; HCC, Hepatocellular carcinoma; $\mathrm{SD}$, Standard deviation

${ }^{a}$ ACLF grade and classification based on EASL clinical practice guideline [17]

Table 2 Bivariate and multivariate analyses of in-hospital mortality

\begin{tabular}{|c|c|c|c|c|}
\hline \multirow[t]{2}{*}{ Variables } & \multicolumn{2}{|l|}{ Bivariate analysis } & \multicolumn{2}{|l|}{ Multivariate analysis } \\
\hline & OR $(95 \% \mathrm{CI})$ & p-value & Adjusted OR (95\% CI) & p-value \\
\hline Age (years) & $1.07(1.03-1.11)$ & $<0.001$ & $1.09(1.03-1.14)$ & 0.001 \\
\hline Charlson Comorbidities & $1.23(0.74-2.03)$ & 0.416 & & \\
\hline Previous acute decompensation & $0.61(0.20-1.85)$ & 0.383 & & \\
\hline Hepatic encephalopathy & $3.47(1.56-7.68)$ & 0.002 & & \\
\hline Bacterial infection & $9.27(3.93-21.84)$ & $<0.001$ & $6.25(2.31-16.92)$ & $<0.001$ \\
\hline MAP & $0.98(0.96-1.01)$ & 0.234 & & \\
\hline $\mathrm{SpO}_{2} / \mathrm{FiO}_{2}$ ratio & $4.60(1.88-11.25)$ & 0.001 & & \\
\hline Neutrophil count (In) & $2.89(1.54-5.43)$ & 0.001 & & \\
\hline Sodium & $0.90(0.85-0.96)$ & $<0.001$ & & \\
\hline Albumin & $0.42(0.21-0.80)$ & 0.009 & & \\
\hline Total bilirubin (In) & $2.58(1.77-3.77)$ & $<0.001$ & $3.01(1.85-4.89)$ & $<0.001$ \\
\hline Creatinine (In) & $3.59(1.79-7.18)$ & $<0.001$ & $2.70(1.20-6.05)$ & 0.016 \\
\hline Prothrombin time (I/sqr) & $2.17(1.05-4.46)$ & $<0.001$ & & \\
\hline
\end{tabular}

In, natural logarithm; MAP, mean arterial pressure

Table 3 Multivariate logistic regression analysis with backward stepwise method $(n=241)$

\begin{tabular}{lrrrr}
\hline Variables & B & SE & Z & p-value \\
\hline Age & 0.086 & 0.025 & 3.42 & 0.001 \\
Bacterial infection & 1.834 & 0.507 & 3.61 & $<0.001$ \\
Total bilirubin (In) & 1.101 & 0.248 & 4.44 & $<0.001$ \\
Creatinine (In) & 0.994 & 0.411 & 2.42 & 0.016 \\
Constant & -9.299 & 1.762 & -5.28 & $<0.001$ \\
\hline
\end{tabular}

In: natural logarithm, SE: standard error, Z: B/SE in-hospital mortality was calculated by equation: $\mathrm{p}=1 /$ $(1+\exp (-\mathrm{y}))$, with $\mathrm{y}=1.132 \times$ additive score -4.670 . The discriminatory power of the additive score was good (AUROC: 0.868 ; 95\% CI: 0.806-0.930), and a cutoff $\geq 3$ had a sensitivity of $72.4 \%$ and a specificity of $83 \%$ (Fig. 2). The observed and expected probabilities of inhospital mortality across different levels of the additive score were similar (Additional file 1: Table S2, Figure S3). The Hosmer-Lemeshow test also indicated a good fit $\left(\mathrm{x}^{2}=1.17 ; p=0.7595\right)$. The AUROC of the additive score 


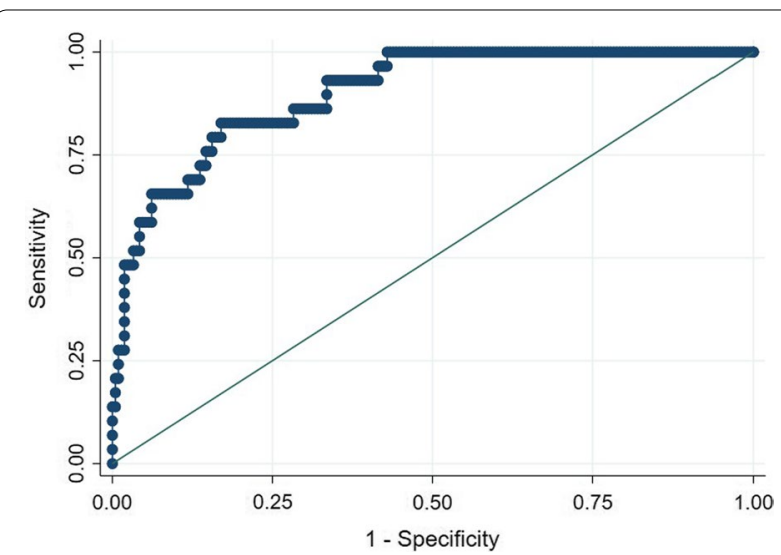

Fig. 1 Receiver operating characteristic curve for the logistic score. AUROC: 0.899

Table 4 Multivariate logistic regression analysis of the additive score

\begin{tabular}{lrrrr}
\hline Variables & B & SE & z & p-value \\
\hline Age & 1.116 & 0.491 & 2.27 & 0.023 \\
Bacterial Infection & 1.935 & 0.495 & 3.91 & $<0.001$ \\
Total bilirubin & 1.400 & 0.507 & 2.76 & 0.006 \\
Creatinine & 1.509 & 0.497 & 3.03 & 0.002 \\
Constant & -4.859 & 0.650 & -7.48 & $<0.001$ \\
\hline
\end{tabular}

SE: standard error; Z: B/SE

Table 5 Additive scoring system for in-hospital mortality

\begin{tabular}{lll}
\hline Variables & Category & Score \\
\hline Age & $<57$ years old & 0 \\
& $\geq 57$ years old & 1 \\
Bacterial infection & No & 0 \\
Total bilirubin $(\mathrm{mg} / \mathrm{dL})$ & $<3$ & 2 \\
& $\geq 3$ & 0 \\
Creatinine $(\mathrm{mg} / \mathrm{dL})$ & $<1.1$ & 1 \\
& $\geq 1.1$ & 0 \\
\hline
\end{tabular}

was significantly better than that of CLIF-C OF score $(p=0.0151)$, but not significantly better than those of $\operatorname{MELD}(p=0.3097)$ and MELD-Na $(p=0.2451)$ (Table 6).

\section{Discussion}

Previously, we reported the long-term prognosis of hospitalized cirrhotic patients [18]. This study involved 241 adult patients with acutely decompensated liver cirrhosis and an in-hospital mortality rate of $12.03 \%$. We identified independent predictors of in-hospital mortality and then

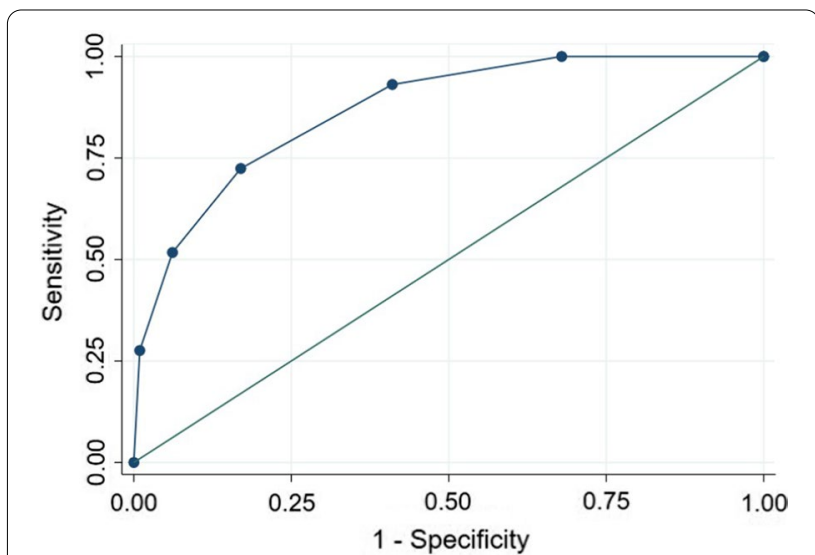

Fig. 2 Receiver operating characteristic curve for the additive score. AUROC: 0.868

Table 6 Discrimination ability of logistic and additive score as compared to MELD, MELD-Na, CLIF-C OF $(n=241)$

\begin{tabular}{lllll}
\hline Score & AUROC & $\mathbf{9 5 \% C l}$ & $\boldsymbol{p}$-value & \\
\cline { 3 - 5 } & & & vs. Logistic score & $\begin{array}{l}\text { vs. Additive } \\
\text { score }\end{array}$ \\
\hline Logistic & 0.899 & $0.846-0.952$ & & \\
Additive & 0.868 & $0.806-0.930$ & & 0.3097 \\
MELD & 0.826 & $0.751-0.902$ & 0.0432 & 0.2451 \\
MELD-Na & 0.831 & $0.758-0.903$ & 0.0142 & 0.0151 \\
CLIF-C OF & 0.752 & $0.656-0.847$ & 0.0005 & \\
\hline
\end{tabular}

MELD, Model for end-stage liver disease; MELD-Na, Model for end-stage live disease-sodium; CLIF-C OF, Chronic liver failure-consortium organ failure

developed predictive scoring systems for daily clinical application.

The majority of the patients in this study were male, with a mean age of 53 years old and Child-Pugh class $\mathrm{B}$ or $\mathrm{C}$ cirrhosis. This is similar to the characteristics of hospitalized liver cirrhosis patients reported by multinational prospective studies in Europe (the CANONICEASL-CLIF/Acute-on-Chronic Liver Failure in Cirrhosis study) and North America (NACSLED/North American Consortium for the Study of End-Stage Liver Disease study) $[7,19,20]$. In the CANONIC and NACSLED studies, the most common aetiologies of liver cirrhosis were alcohol consumption and hepatitis C. However, this study found that the most common etiology was hepatitis $B$. This is consistent with the epidemiological data of hepatitis B infection in Indonesia. One-third of the subjects also had diabetes mellitus, similar to that reported in the NACSLED study.

In this study, $70.95 \%$ of the subjects presented with gastrointestinal bleeding, whereas in the CANONIC study, most of the liver cirrhosis patients were treated 
for hepatic encephalopathy and ascites [19]. The high proportion of gastrointestinal bleeding in this study is thought to be associated with the degree of increased portal venous pressure, given that portal vein pressure measured indirectly by the hepatic venous pressure gradient (HVPG) is significantly higher in Child-Pugh B and $\mathrm{C}$ cirrhosis than in Child-Pugh A cirrhosis [21]. A total of $25.31 \%$ of subjects had bacterial infections, with the most common types being pneumonia, spontaneous bacterial peritonitis, and urinary tract infection, similar to that previously reported [22].

The in-hospital mortality rate in this cohort was $12.03 \%$, which was relatively higher than that previously reported [6, 23-26]. A systematic analysis of the mortality rates of liver cirrhosis patients in 187 countries by Mokdad et al. indicated a 22\% decline in the 1980-2010 period in developed countries in Europe, China, and the United States, while in Indonesia, this figure had increased. Lower mortality rates in developed countries were associated with improved preventive measures, such as hepatitis screening for blood donors, hepatitis B vaccination, and alcohol consumption restrictions [3].

This study found that age, bacterial infection, bilirubin, and creatinine level were all predictors of in-hospital mortality in acutely decompensated liver cirrhosis patients. Similar results were also reported in other studies $[6,7,20,24]$. These studies have consistently shown a significant association between age and mortality due to liver cirrhosis. However, in line with previous studies, we found that age was not the major predictor of in-hospital mortality in acutely decompensated liver cirrhosis $[8,20$, 24].

Bacterial infection is commonly diagnosed in $20-25 \%$ of liver cirrhosis patients [27]. Similar to that in previous studies, we found that bacterial infection had a strong association with in-hospital mortality (adjusted OR: 6.25, 95\% CI: 2.31-16.92, $\mathrm{p}<0.001)$ [19, 27-29]. Therefore, early diagnosis and treatment of bacterial infection should be routinely performed in patients with acutely decompensated liver cirrhosis. The diagnosis of bacterial infection using leukocyte count is often difficult in liver cirrhosis patients due to hypersplenism. In addition, leukocytosis occurs in only $<50 \%$ of patients with infection. A study by Li $Y$ et al. showed that the neutrophil percentage was associated with 90-day mortality in advanced liver cirrhosis patients with bacterial infection [16]. In our study, the median neutrophil count was higher in the nonsurvivors than in the survivors, and it was significantly associated with in-hospital mortality in the univariate analysis but not in the multivariate analysis. Other studies have shown that mortality due to liver cirrhosis is associated with decreased chemotaxis and the phagocytosis capacity of neutrophils [30].
The increased systemic inflammatory response in acutely decompensated liver cirrhosis patients could cause liver and extrahepatic organ dysfunction. The bilirubin level is routinely measured as a marker of liver cirrhosis. The Asian Pacific Association for the Study of the Liver (APASL) consensus on acute-on-chronic liver failure (ACLF) suggested that a bilirubin level of $5-10 \mathrm{mg} /$ $\mathrm{dL}$ was associated with a mortality rate of $38 \%$ [31]. The CANONIC study showed that a bilirubin level $\geq 12 \mathrm{mg} /$ $\mathrm{dL}$ was associated with a 28 -day mortality rate of $15 \%$ [19]. A study by López-Velázquez et al. showed that a bilirubin level $\geq 3.45 \mathrm{mg} / \mathrm{dL}$ at admission predicted oneweek mortality in decompensated cirrhotic patients with ACLF [32]. Accordingly, we also found that the total bilirubin level was an independent predictor of in-hospital mortality.

Renal dysfunction in acutely decompensated liver cirrhosis patients may occur as a result of hypovolemia or bleeding, bacterial infection, hepatorenal syndrome, renal parenchymal abnormalities, use of drugs or contrast agents, or a combination of these factors. The inhospital mortality rate in acutely decompensated liver cirrhosis patients with type 1 hepatorenal syndrome was higher than those with bleeding or hypovolemia [33]. Our study showed that each incremental increase in creatinine increased the risk of in-hospital mortality by up to three times, independent of bacterial infection. This indicates that antibiotic therapy alone may not be sufficient to reduce the risk of in-hospital mortality. Therefore, close monitoring of renal function is imperative in acutely decompensated liver cirrhosis patients. Currently, international consensus recommends albumin for all cirrhotic patients with spontaneous bacterial peritonitis and hepatorenal syndrome to reduce mortality and improve renal function [17].

The economic burden of treating decompensated liver cirrhosis patients is very high, and prognostic models or scoring systems could help clinicians deliver more costeffective care to these patients [34]. In this study, we developed predictive scoring systems using clinical data obtained routinely at the time of hospital admission in both additive and logistic forms. Both the logistic and additive scoring systems showed good discriminatory powers. The simple additive form is calculated by adding up scoring points, so it can be performed bedside in a resource-limited clinical setting. The logistic form needs complex calculations with slightly improved accuracy. Therefore, the logistic score can be integrated into hospital information technology system for more precise, predictive analysis. Furthermore, we found that the logistic score showed better discrimination ability compared to other scores such as MELD, MELD-Na and CLIF-C OF. 
There are several limitations to our study. This study was a single-centre, retrospective cohort study and is therefore susceptible to information bias. In daily clinical practice, using our scoring systems at the time of hospital admission could help clinicians with an early screening of high-risk patients. However, further studies are needed to see whether a serial assessment of the scoring systems throughout hospitalization also correlate with mortality outcome. Previous studies showed that in high-risk patients with variceal bleeding (HVPG $\geq 20 \mathrm{mmHg}$, Child-Pugh B with active bleeding or Child-Pugh $C \leq 13$ ), pre-emptive TIPSS improved the long-term mortality rate $[35,36]$. Pre-emptive TIPSS was also associated with decreased in-hospital mortality [37]. Due to resources limitation at our institution, none of our patients were treated with TIPSS. Further studies are needed to confirm whether our scoring systems could also select those high-risk patients who are candidates for pre-emptive TIPSS. Further validation of our proposed predictive scoring systems in different populations is needed to confirm our findings.

\section{Conclusion}

In conclusion, the in-hospital mortality rate of acutely decompensated liver cirrhosis patients in Indonesia is still high. Age, bacterial infection, total bilirubin, and creatinine levels were independent predictors of in-hospital mortality. The scoring systems for daily clinical use, in the form of a logistic score and an additive score, can be used to predict in-hospital mortality in acutely decompensated liver cirrhosis patients.

\begin{abstract}
Abbreviations
ACLF: Acute-on-chronic liver failure; APASL: Asian Pacific Association for the Study of the Liver; AUROC: Area under the ROC curve; CANONIC: Chronic liver failure (CLIF) acute-on-chronic liver failure in cirrhosis; CLIF-AD: Chronic liver failure-acute decompensation; CLIF-C OF: Chronic liver failure-consortium organ failure; EASL-CLIF: European Association for the Study of the LiverChronic Liver Failure; CT: Computed tomography; HCC: Hepatocellular carcinoma; HIV: Human immunodeficiency virus; HVPG: Hepatic venous pressure gradient; MAP: Mean arterial pressure; MELD: Model for End-Stage Liver Disease; MELD-Na: MELD-sodium; MRI: Magnetic resonance imaging; NACSLED: North American Consortium for the Study of End-Stage Liver Disease; NAFLD: Nonalcoholic fatty liver disease; OR: Odds ratio; ROC: Receiver operating characteristic; TIPSS: Transjugular intrahepatic portosystemic shunt.
\end{abstract}

\section{Supplementary Information}

The online version contains supplementary material available at https://doi. org/10.1186/s12876-021-01972-6.

Additional file 1. Figure S1. The flow chart of the cohort study. Table S1. Contingency tables for the Hosmer-Lemeshow test for the logistic score. Table S2. Contingency tables for the Hosmer-Lemeshow test for the additive score. Figure S2. Calibration plot for the logistic score (Spearman's rho $=0.9147 ; p=0.0002$. Figure S3. Calibration plot for the additive score (Spearman's rho $=0.9747 ; p=0.0048$ ).

\section{Acknowledgements}

The authors express thanks to Siti Nurohma for assisting with data collection and analysis.

\section{Authors' contributions}

Saut HHN: conception, study design, data collection and analysis, manuscript writing, and revision. AM: study design, statistical analysis, interpretation of data, manuscript revision. AF: conception, study design, supervision of the study, manuscript revision. RAG: conception, study design, supervision of the study, manuscript revision. All authors read and approved the final manuscript.

\section{Funding}

Not applicable.

\section{Availability of data and materials}

The datasets analysed during the current study are available from the corresponding author on reasonable request.

\section{Declarations}

\section{Ethics approval and consent to participate}

This study was performed in accordance with the ethical principles of the Declaration of Helsinki (7th revision, 2013). This study was approved by the Ethics Committee of the Faculty of Medicine, Universitas Indonesia (No. KET-1368/UN2.F1/ETIK/PPM.00.02/2019) and the Institutional Review Board of Cipto Mangunkusumo National General Hospital (No.LB.02/221/0107/2020). The Ethics Committee of the Faculty of Medicine, Universitas Indonesia waived the need for written consent as this was a retrospective study using the hospital database without any intervention to the patient. All data used is kept confidential.

\section{Consent for publication \\ Not applicable.}

\section{Competing interests}

The authors declare that they have no competing interests.

\section{Author details}

${ }^{1}$ Hepatobiliary Division, Internal Medicine Department, Cipto Mangunkusumo National General Hospital, Faculty of Medicine, Universitas Indonesia, Jl. Diponegoro No. 71, Jakarta 10430, Indonesia. ${ }^{2}$ Clinical Epidemiology Unit, Internal Medicine Department, Cipto Mangunkusumo National General Hospital, Faculty of Medicine, Universitas Indonesia, Jl. Diponegoro No.71, Jakarta 10430, Indonesia. ${ }^{3}$ Gastroenterology Division, Internal Medicine Department, Cipto Mangunkusumo National General Hospital, Faculty of Medicine, Universitas Indonesia, J. Diponegoro No.71, Jakarta 10430, Indonesia.

Received: 22 November 2020 Accepted: 14 October 2021

Published online: 20 October 2021

\section{References}

1. GBD 2017 Causes of Death Collaborators. Global, regional, and national age-sex-specific mortality for 282 causes of death in 195 countries and territories, 1980-2017: a systematic analysis for the Global Burden of Disease Study 2017. Lancet. 2018; 392: 1736-88. https://doi.org/10.1016/ S0140-6736(18)32203-7.

2. Wong MCS, Huang JLW, George J, Huang J, Leung C, Eslam M, et al. The changing epidemiology of liver diseases in the Asia-Pacific region. Nat Rev Gastroenterol Hepatol. 2019;16(1):57-73. https://doi.org/10.1038/ s41575-018-0055-0.

3. Mokdad AA, Lopez AD, Shahraz S, Lozano R, Mokdad AH, Stanaway J, et al. Liver cirrhosis mortality in 187 countries between 1980 and 2010: a systematic analysis. BMC Med. 2014;12(145):1-24. https://doi.org/10. 1186/s12916-014-0145-y.

4. Marchesini G, Bianchi G, Amodio P, Salerno F, Merli M, Panella C, et al. Factors associated with poor health-related quality of life of patient with cirrhosis. Gastroenterology. 2001; 120:170-8. https://doi.org/10.1053/ gast.2001.21193. 
5. D’Amico G, Garcia-Tsao G, Pagliaro L. Natural history and prognostic indicators of survival in cirrhosis: a systematic review of 118 studies. J Hepatol. 2006;44:217-31. https://doi.org/10.1016/j.jhep.2005.10.013.

6. Vergara M, Cleries M, Vela E, Bustins M, Miquel M, Campo R. Hospital mortality over time in patients with specific complications of cirrhosis. Liver Int. 2013;33:828-33. https://doi.org/10.1111/liv.12137.

7. Jalan R, Pavesi M, Saliba F, Amoros A, Fernandez J, Holland-Fischer P, et al. The CLIF consortium acute decompensation score for prognosis of hospitalized cirrhotic patients without acute-on-chronic liver failure. J Hepatol. 2015;62(4):831-40. https://doi.org/10.1016/j.jhep.2014.11.012.

8. Chen CY, Wu CJ, Pan CF, Chen HH, Chen YW. Influence of age on critically ill patients with cirrhosis. Int J Gerontol. 2015;9:233-8. https://doi.org/10. 1016/j.ijge.2014.10.003.

9. Levesque E, Hoti E, Azoulay D, Ichai P, Habouchi H, Castaing D, et al. Prospective evaluation of the prognostic scores for cirrhotic patients admitted to an intensive care unit. J Hepatol. 2012;56:95-102. https://doi. org/10.1016/j.jhep.2011.06.024.

10. Alsultan MA, Alrshed RS, Aljumah AA, Baharoon SA, Arabi YM, Aldawood AS. In-hospital mortality among a cohort of cirrhotic patients admitted to a tertiary hospital. Saudi J Gastroenterol. 2011;17:387-90. https://doi.org/ 10.4103/1319-3767.87179

11. Lazzarotto C, Ronsoni MF, Fayad L, Nogueira CL, Bazzo ML, NarcisoSchiavon JL, et al. Acute phase proteins for the diagnosis of bacterial infection and prediction of mortality in acute complications of cirrhosis. Ann Hepatol. 2013;12(4):431-9.

12. Chang-Chyi J, Ming-Hung T, Ya-Chung T, Ming-Yang C, Chan-Yu L, JauMin $L$, et al. Serum sodium predicts prognosis in critically ill cirrhotic patients. J Clin Gastroenterol. 2010;44(3):220-6. https://doi.org/10.1097/MCG. Ob013e3181aabbcd.

13. Wu SL, Zheng YX, Tian ZW, Chen MS, Tan HZ. Scoring system for prediction of mortality in decompensated liver cirrhosis: a meta-analysis of test accuracy. World J Clin Cases. 2018; 6(15):9951006. https://doi.org/10. 12998/wjcc.v6.i15.995.

14. Cavallazzi R, Awe OO, Vasu TS, Hirani A, Vaid U, Leiby BE, et al. Model for End-Stage Liver Disease score for predicting outcome in critically ill medical patients with liver cirrhosis. J Crit Care. 2012;27:424.e1-424.e6. https:// doi.org/10.1016/j.jcrc.2011.11.014.

15. Agustina R, Dartanto T, Sitompul R, Susiloretni KA, Suparmi, Achadi EL, et al. On behalf of the Indonesia Health Systems Group. Universal health coverage in Indonesia: concept, progress, and challenges. Lancet. 2019;393(10166):75-102. https://doi.org/10.1016/S0140-6736(18) 31647-7.

16. Li Y, Chaiteerakij R, Kwon JH, Jang JW, Lee HL, Cha S, et al. A model predicting short-term mortality in patients with advanced liver cirrhosis and concomitant infection. Medicine. 2018;97(41):e12758. https://doi.org/10. 1097/MD.0000000000012758.

17. European Association for the Study of the Liver. EASL Clinical Practice Guidelines for the management of patients with decompensated cirrhosis. J Hepatol. 2018;69(2):406-60. https://doi.org/10.1016/j.jhep.2018. 03.024.

18. Gani RA, Hasan I, Sulaiman AS, Lesmana CRA, Kurniawan J, Zulkifly S Scoring system for predicting the 90-days mortality among hospitalized cirrhotic patients: a lesson learnt from national referral hospital [abstract]. Hepatol Int. 2019;13(Suppl 1):S245.

19. Moreau R, Jalan R, Gines P, Pavesi M, Angeli P, Cordoba J, et al. Acute-onChronic Liver Failure is a distinct syndrome that develops in patients with acute decompensation of cirrhosis. Gastroenterology. 2013;144:1426-37. https://doi.org/10.1053/j.gastro.2013.02.042.

20. O'Leary JG, Reddy KR, Garcia-Tsao G, Biggins SW, Wong F, Fallon MB, et al. NACSELD Acute-on-Chronic Liver Failure (NACSELD-ACLF) Score predicts 30-day survival in hospitalized patients with cirrhosis. Hepatology. 2018;67(6):2367-74. https://doi.org/10.1002/hep.29773.

21. Ramanathan S, Khandelwal N, Kalra N, Bhatia A, Dhiman RK, Duseja AK, et al. Correlation of HVPG level with CTP score, MELD score, ascites, size of varices, and etiology in cirrhotic patients. Saudi J Gastroentero. 2016;22(2):109-15. https://doi.org/10.4103/1319-3767.164185.

22. Jalan R, Fernandez J, Wiest R, Schnabl B, Moreau R, Angeli P, et al. Bacterial infections in cirrhosis: a position statement based on the EASL special conference 2013. J Hepatol. 2014;60:1310-24. https://doi.org/10.1016/j. jhep.2014.01.024.

23. Charif I, Saada K, Mellouki I, El Yousfi M, Benajah D, El Abkari M, et al. Predictors of intra-hospital mortality in patients with cirrhosis. Open J Gastroenterol. 2014;4:141-8. https://doi.org/10.4236/ojgas.2014.43021.

24. Charatcharoenwitthaya P, Soonthornworasiri N, Karaketklang K, Poovorawan K, Panngum W, Chotiyaputta W, et al. Factors affecting mortality and resource use for hospitalized patients with cirrhosis: a populationbased study. Medicine. 2017;96(32):e7782. https://doi.org/10.1097/MD. 0000000000007782.

25. Schmidt ML, Barritt AS, Orman ES, Hayashi PH. Decreasing mortality among patients hospitalized with cirrhosis in the United States from 2002 through 2010. Gastroenterology. 2015;148:967-77. https://doi.org/10. 1053/j.gastro.2015.01.032

26. Xu Y, Li N, Lu M, Dixon E, Myers RP, Jolley RJ, et al. Comparison of risk adjustment methods in patients with liver disease using electronic medical record data. BMC Gastroenterol. 2017;17(5). https://doi.org/10.1186/ s12876-016-0559-4.

27. Singal AK, Salameh H, Kamath PS. Prevalence and in-hospital mortality trends of infections among patients with cirrhosis: a nationwide study of hospitalised patients in the United States. Aliment Pharmacol Ther. 2014;40:105-12. https://doi.org/10.1111/apt.12797.

28. Dionigi E, Garcovich M, Borzio M, Leandro G, Majumdar A, Tsami A, et al. Bacterial infections change natural history of cirrhosis irrespective of liver disease severity. Am J Gastroenterol. 2017;112(4):588-96. https://doi.org/ 10.1038/ajg.2017.19.

29. Arvaniti V, D'Amico G, Fede G, Manousou P, Tsochatzis E, Pleguezuelo $M$, et al. Infections in patients with cirrhosis increase mortality fourfold and should be used in determining prognosis. Gastroenterology. 2010;139:1246-56. https://doi.org/10.1053/j.gastro.2010.06.019.

30. Irvine KM, Ratnasekera I, Powell EE, Hume DA. Causes and consequences of innate immune dysfunction in cirrhosis. Front Immunol. 2019;10:1-14. https://doi.org/10.3389/fimmu.2019.00293.

31. Sarin SK, Choudhury A, Sharma MK, Maiwall R, Al Mahtab M, Rahman S, et al. Acute-on-chronic liver failure: consensus recommendations of the Asian Pacific association for the study of the liver (APASL): an update. Hepatol Int. 2019;13:353-90. https://doi.org/10.1007/ s12072-019-09946-3.

32. López-Velázquez JA, Chávez-Tapia NC, Ponciano-Rodríguez G, SánchezValle V, Caldwell SH, Uribe M, et al. Bilirubin alone as a biomarker for shortterm mortality in acute-on-chronic liver failure: an important prognostic indicator. Ann Hepatol. 2014;13(1):98-104.

33. de Carvalho GC, de Andrade RC, Kalil JR, Cerqueira LA, Barbosa DS, Motta MP, et al. Causes of renal failure in patients with decompensated cirrhosis and its impact in hospital mortality. Ann Hepatol. 2012;11(1):90-5.

34. Desai AP, Mohan P, Nokes B, Sheth D, Knapp S, Boustani M et al. Increasing economic burden in hospitalized patients with cirrhosis: analysis of a national database. Clin Trans Gastroen. 2019;10(7):1-10. https://doi.org/ 10.14309/ctg.0000000000000062.

35. García-Pagán JC, Caca K, Bureau C, Laleman W, Appenrodt B, Luca A, et al. Early TIPS (Transjugular Intrahepatic Portosystemic Shunt) Cooperative Study Group. Early use of TIPS in patients with cirrhosis and variceal bleeding. N Engl J Med. 2010;362(25):2370-9. https://doi.org/10.1056/ NEJMoa0910102.

36. Monescillo A, Martínez-Lagares F, Ruiz-del-Arbol L, Sierra A, Guevara C,

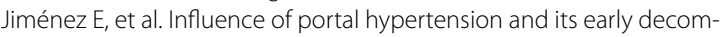
pression by TIPS placement on the outcome of variceal bleeding. Hepatology. 2004;40(4):793-801. https://doi.org/10.1002/hep.20386.

37. Njei B, McCarty TR, Laine L. Early transjugular intrahepatic portosystemic shunt in US patients hospitalized with acute esophageal variceal bleeding. J Gastroenterol Hepatol. 2017;32(4):852-8. https://doi.org/10.1111/ jgh.13593.

\section{Publisher's Note}

Springer Nature remains neutral with regard to jurisdictional claims in published maps and institutional affiliations. 